\title{
ANÁLISIS MULTITEMPORAL DEL USO DE SUELO VALLE LO CAMPINO, QUILICURA.
}

\section{MULTI-TEMPORAL ANALYSIS OF LAND USE. VALLEY LO CAMPINO, QUILICURA.}

\author{
Sr. Fabricio Álvarez Flores ${ }^{1}$ \\ Sra. Fabiola Barrenechea Riveros ${ }^{2}$
}

\section{RESUMEN}

La presente investigación, aborda el cambio de cobertura de suelo a través de un análisis multitemporal entre los años 1998-2018, en la comuna de Quilicura, Región Metropolitana, en un área denominada Valle Lo Campino, definido por el Cerro Renca y sus estribaciones. Para ello, se realizó una clasificación supervisada en periodos de cinco años a partir de imágenes satelitales, apoyo de Google Earth y la clasificación temática de uso del suelo establecida por la Corporación Nacional Forestal el año 2011. A partir de esta, se determinó cualitativamente y cuantitativamente los cambios del territorio en función de cartografía temática y una matriz de confusión. Complementariamente, se determinó el aumento poblacional en función de datos publicados para el 2017 por el Instituto de Estadísticas de Chile y la determinación de carga vehicular potencial establecida en terreno, con apoyo de unidades muestrales. En conjunto, el análisis, es la base para la identificación y mejoramiento vial del área y su conectividad a vías estructurantes, desde la perspectiva de imagen objetivo, con apoyo de metodologías e insumos propios de la geomática, conceptos topográficos, la proyección de nuevas alternativas viales y apoyo de terreno. Paralelamente, se plantea una propuesta paisajística que potencie las características geográficas y el valor del paisaje, obtenido de la guía de evaluación ambiental presentada por el Servicio de Evaluación de Impacto ambiental y el carácter de cerro isla del Cerro Renca dentro de la Región Metropolitana.

Palabras Claves: Análisis multitemporal, cambio uso suelo, alternativas viales, propuesta paisajística.

\section{ABSTRACT}

The present investigation deals with the change of land cover through a multitemporal analysis between the years 1998-2018, in the commune of Quilicura, Metropolitan Region, in an area called Valle Lo Campino, defined by Cerro Renca and its foothills. For this purpose, a supervised classification was carried out in fiveyear periods based on satellite images, Google Earth support and the land use thematic classification established by the National Forest Corporation in 2011. From this, it was determined qualitatively and quantitatively change the territory according to thematic cartography and a confusion matrix. In addition, the population increase was determined based on data published for 2017 by the Statistics Institute of Chile and the determination of potential vehicular load established in the field, with the support of sample units. Overall, the analysis is the basis for road identification and improvement of the area and its connectivity to structuring routes, from the perspective of objective image, with the support of methodologies and inputs from geomatics, topographic concepts, the projection of new alternatives vials and ground support. At the same time, a landscape proposal is proposed that enhances the geographical characteristics and the landscape value, obtained from the environmental assessment guide presented by the Environmental Impact Assessment Service and the nature of Cerro Renca island within the Metropolitan Region.

Key Words: Multitemporal analysis, land use change, road alternatives, landscaping proposal.

\footnotetext{
${ }^{1}$ Escuela Ciencias de la Tierra, Universidad Bernardo O’Higgins, fabricioa@pregrado.ubo.cl

2 Escuela Ciencias de la Tierra, Universidad Bernardo O’Higgins, fabiola.barrenechea@.ubo.cl
}

Fecha de Recepción: 16 de julio de 2019

Fecha de Aprobación: 13 de noviembre de 2019 


\section{INTRODUCCIÓN.}

El crecimiento poblacional ha significado a lo largo de la historia, tanto a escala nacional como mundial, una serie de transformaciones en la estructura y composición de las ciudades (Borsdorf, 2000).

Entendiendo que el cambio de uso del suelo es un proceso dinámico, estos son producto de factores ambientales, demográficos, económicos y socioculturales, que influyen en el cambio de cobertura superficial (Bocco, 2001), los que a su vez producen una serie de cambios geográficos, ecológicos y urbanos como consecuencia de fenómenos de deforestación, urbanización y metropolización. Dado lo anterior, se puede suponer entonces que estas variables son los principales factores de cambios de cobertura de uso de suelo en la dimensión espacio-temporal (Cuadrado, 2016).

Sin embargo, los fenómenos y cambios territoriales, naturales o antrópicos, se han visto potenciado por la carencia de instrumentos de planificación territorial sensibles y flexibles a las formas de ocupación no tradicionales (Cooper, 2007).

Cross (2016) señala que, en Chile, el ordenamiento territorial asociado al crecimiento urbano es una tarea que consiste básicamente en establecer roles para los distintos lugares, zonas específicas asociadas a usos (de suelos), jerarquías, vialidades y distintas áreas para la convivencia del medio natural, los centros poblados y la estructura de movilidad, entre otros. Considerando dentro de estos lo que tiene relación a estructuras viales de las ciudades y el paisaje mirado desde un punto de vista de valor visual y en concordancia con las estructuras ambientales presentes.

En el caso local, las ciudades chilenas, como varias en el mundo, se encuentran en un fuerte proceso de expansión. Este crecimiento casi incontrolado de las ciudades se ha gatillado debido al cambio de usos y coberturas de suelos, transformando espacios naturales o seminaturales en urbanos (Romero et al., 2007), donde prevalecen los instrumentos de planificación territorial de índole normativo, llámese Plan Regulador Metropolitano de Santiago (PRMS) y Planes Reguladores Comunales (PRC), para el caso del estudio, por sobre la investigación.

Por su parte, de acuerdo a lo señalado por el Ministerio de Bienes Nacionales, la Provincia de Santiago presenta treinta y dos comunas que han crecido de forma importante en los últimos años.
Gran parte de este crecimiento se ha manifestado como una densificación de sus áreas centrales. Sin embargo, parte no menor de este crecimiento ha sido con desarrollos inmobiliarios de baja densidad que han ido extendiendo la periferia de la ciudad. De hecho, la mancha urbana de Santiago aumentó su tamaño en un $26 \%$ en tan sólo 10 años (Hurtubia y Cox, 2017), tendencia ya establecida por Ducci (2002) quien señaló que Santiago experimentó un crecimiento en su área urbana entre los años 1991 y 2000 de 12.050 hectáreas, lo que significó un crecimiento de un $25 \%$, principalmente en las comunas centrales y pericentrales.

Munzenmayer (2017) grafica el crecimiento urbano en Santiago junto con su área urbanizable en cincuenta años, llámese PRMS y sus modificaciones (Fig. 1), donde se enfatiza el aumento de la mancha urbana de 21.165 hectáreas en 1940 a 64.140 en el 2002, principalmente a sectores periféricos presionando a terrenos agrícolas, zonas de bosque nativo y sectores altos del faldeo cordillerano andino.

Hurtubia y Cox (2017), por su parte, señalan que el crecimiento de las ciudades es inevitable y viene de la mano del crecimiento demográfico y económico. Fuentes del último Censo realizado por el Instituto Nacional de Estadísticas (INE) señalan que, de las seis comunas a nivel nacional con una mayor dinámica urbana, cuatro se encuentran en Santiago Tabla 1.

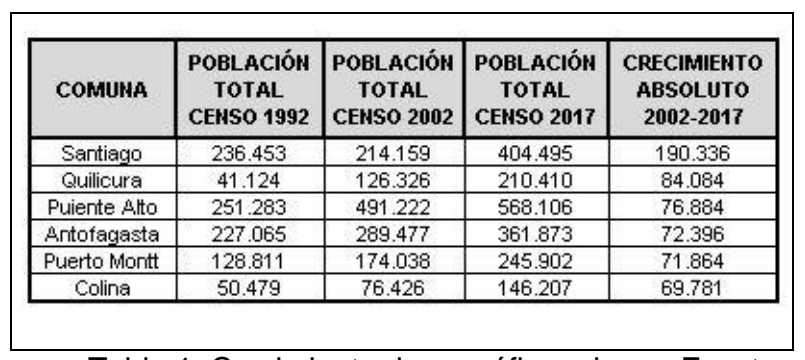

Tabla 1: Crecimiento demográfico urbano. Fuente elaboración propia, basado en INE (Censos de población 2017, 2002, 1992).

La dinámica urbana de ciudades como Antofagasta y Puerto Montt, acompañan a las comunas del Gran Santiago en los puestos de avanzada en términos de expansión demográfica, representando entre los seis municipios principales, más del $11 \%$ de la población nacional (Biblioteca del Congreso Nacional, 2017).

Sánchez (2013) confirma lo señalado por otros autores, indicando que "Los centros urbanos son recipientes de poderosas dinámicas. Dichas 
fuerzas son ejercidas por numerosos actores que en una constante interacción, tensión y conflicto van estableciendo y modificando la morfología y estructura de los asentamientos".

Bajo esta premisa, es necesario involucrar a las distintas ciencias, disciplinas y profesionales que participen y se involucren en el desarrollo, planificación de la ciudad y ser un activo generador de conocimiento, formando un desarrollo más armónico entre el ser humano, las actividades

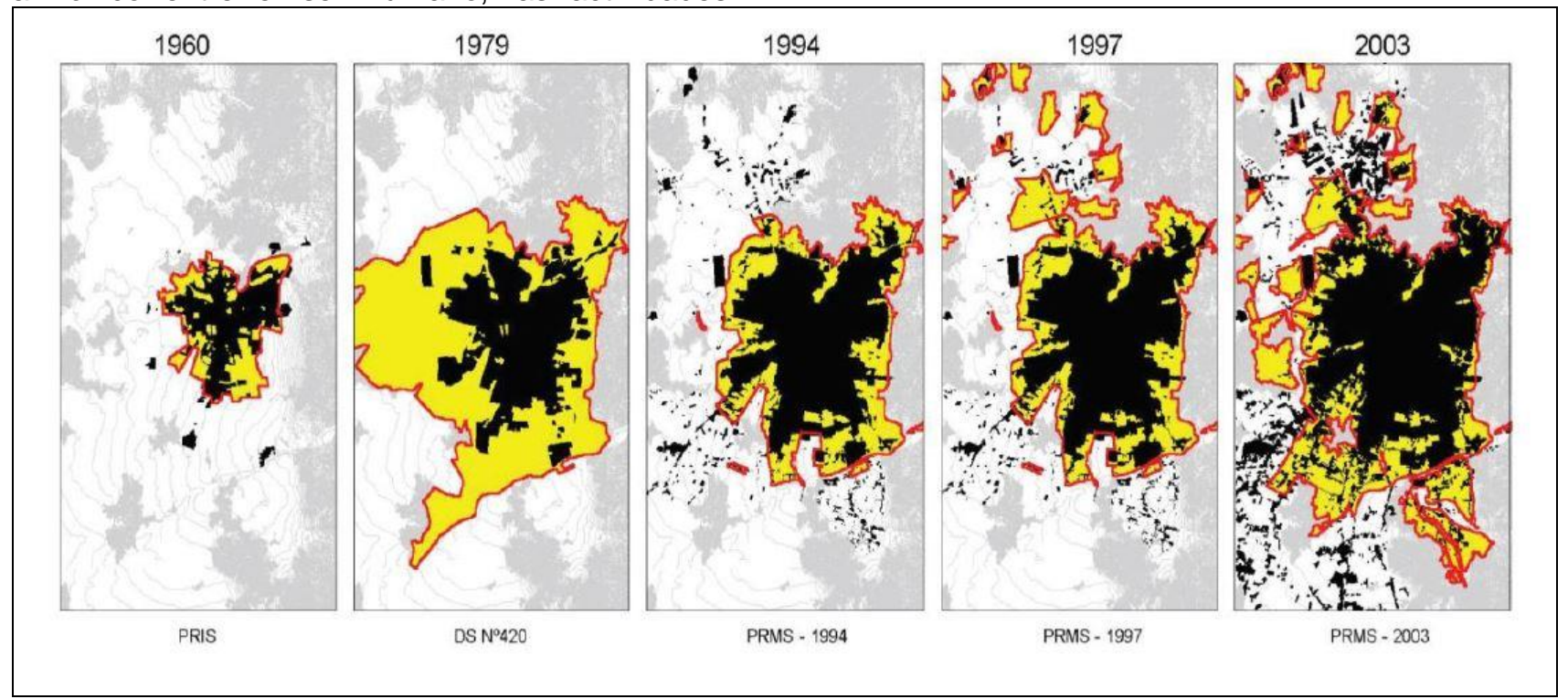

Figura 1: Evolución de los planes reguladores (amarillo) y crecimiento urbano (negro) de Santiago, 1960-2003. Fuente: Poduje, 2006, pp 234.

En el caso del Valle Lo Campino, se identifica una dinámica territorial que está determinada, entre otras, por las relaciones que se establecen entre los actores locales (juntas de vecinos, centros de madres, grupos scout, comerciantes, etc.) para valorizar los recursos territoriales (enfoque dinámico). El enfoque dinámico es considerado, por tanto, una característica inherente al territorio (Sánchez-Zamora, Gallardo-Cobos, y Ceña Delgado, 2016).

\section{MATERIALES Y MÉTODOS}

\section{ÁREA DE ESTUDIO}

El Área de estudio denominado "Valle Lo Campino", se encuentra ubicado en los bordes periurbanos de la Región Metropolitana, Provincia de Santiago, Comuna de Quilicura (Fig. 2), a 9,4 kilómetros del centro de Santiago (Infraestructura de Datos Espaciales, 2016) asociadas y el medio ambiente natural y construido que los rodea. En este contexto, se considera e inserta la Geomática en su globalidad, como una de las ciencias encargada de integrar los medios de captura, procesamiento y análisis de la data georreferenciada y como tal, puede ser usada en diferentes aplicaciones, todas ellas útiles para el desarrollo de los países (Vásquez, 2009). 
artificial, depósitos coluviales y depósitos aluviales del Río Mapocho.

La geomorfología indica que la comuna se encuentra dentro de la depresión intermedia y a nivel local, sus unidades son asociadas a procesos tectónicos y erosivos que, junto a unidades del tipo antropogénico, constituyen y conforman el área y entrega rasgos morfológicos relevantes.

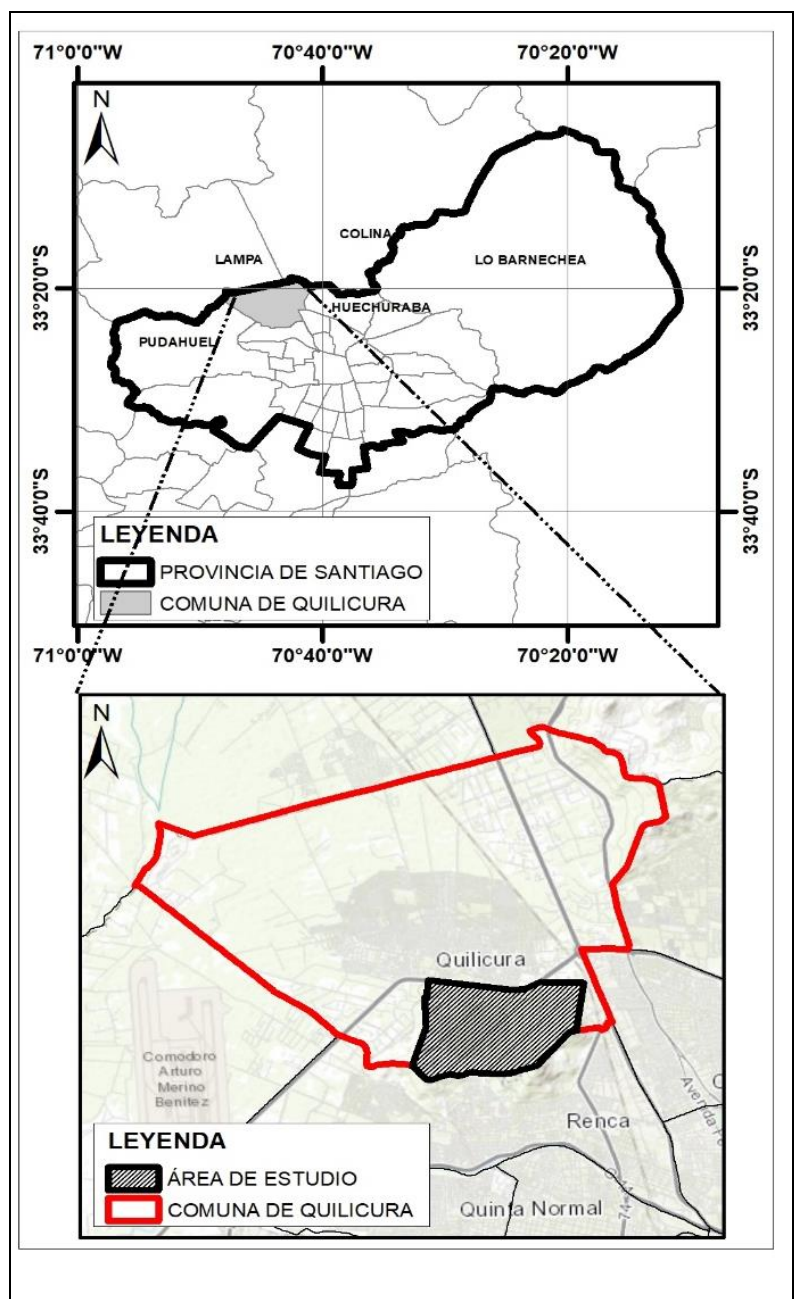

Figura 2: Emplazamiento Valle Lo Campino, respecto a Provincia de Santiago y Comuna de Quilicura. Fuente: Elaboración propia, 2018.

Conforme a la normativa vigente, el área es definida como habitacional mixta, con un emplazamiento que se aproxima a un patrón urbano denominado Barrio Privado.

Para el análisis y cuantificación multitemporal del cambio de suelo del área descrita, se utilizaron imágenes de satélite obtenidas entre los años 1998 y 2018 con resolución espacial de treinta metros, a través del sensor Landsat TM implementado en el satélite Landsat 7 y 8 . Las imágenes fueron obtenidas desde la plataforma virtual del Centro Geológico de los Estados Unidos (USGS, por sus siglas en inglés), con un nivel de procesamiento que considera correcciones del tipo radiométrico, geométrico y topográficos. Se privilegió el uso de imágenes obtenidas durante los meses de enero y febrero, para evitar la presencia de factores climáticos que pueden limitar la visibilidad, clasificación e interpretación de las imágenes satelitales. Conjuntamente, se consideraron imágenes obtenidas desde el satélite Sentinel 2 con una resolución de diez metros. Estas últimas imágenes fueron descargadas desde la plataforma de la Agencia Espacial Europea (ESA) y Google Earth para comparar y apoyar la clasificación de coberturas de suelo de las imágenes de satélite.

El análisis de las imágenes se realizó en series de cinco años (quinquenios), por medio de una clasificación supervisada en los Sistemas de Información Geográfica (SIG) ENVI y ArcGIS, aplicando la categorización de uso del suelo establecida por la Corporación Nacional Forestal (CONAF) el año 2011 (Tabla 2). Se decidió analizar las imágenes en quinquenios principalmente por los proyectos inmobiliarios en el área, los cuales presentan un tiempo de ejecución aproximado de cinco años para cada micro barrio. En la definición de unidades homogéneas de coberturas de suelo, fue apoyado en la etapa final por medio de fotointerpretación clásica o visual, donde se consideraron antecedentes bibliográficos, observaciones de terreno y patrones de fotointerpretación, como formas, tamaños, texturas y otras propiedades visibles (García-Meléndez, 2006).

La cuantificación de cambios de cobertura de suelo fue realizada por medio de álgebra de mapas y geoprocesamientos, los cuales fueron realizados digitalmente en plataformas SIG, específicamente ArcGis 10.4 .1 el año 2018. Este análisis, permite presentar un modelo de matriz de cambio que, para este caso de estudio, estableció una comparación matricial de clases ubicadas en el mapa, confrontando las categorías identificadas de cada lustro. Con esto, se determinó una tasa de cambio anual (TDA) a partir de una ecuación propuesta el año 1996 por la Organización de las Naciones Unidas para la Alimentación (FAO, por sus siglas en inglés).

$$
\text { TDA: Tasa }=\left[\frac{\mathrm{S} 2}{\mathrm{~S} 1}\right] 1 / \mathrm{n}-1
$$


Dónde "TDA" es la tasa de cambio anual, "S2": es la superficie durante la fecha 2 , "S1" es la superficie durante la fecha 1, y "n" es el número de años entre las dos fechas.

\begin{tabular}{|c|c|}
\hline & USOS/SUBUSOS DEL SUELO \\
\hline 1 & $\begin{array}{l}\text { Áreas urbanas e industriales } \\
\text { 1.1 Cuidades, pueblos, zonas industriales } \\
\text { 1.2 Mineria industrial }\end{array}$ \\
\hline 2 & $\begin{array}{l}\quad \text { Terrenos agrícolas } \\
\text { 2.1 Terrenos de uso agrícola } \\
\text { 2.2 Rotación cultivo-pradera } \\
\text { 2.3 Praderas y matorrales }\end{array}$ \\
\hline 3.1 & $\begin{array}{l}\text { Praderas } \\
\text { 3.2 Matorral-pradera } \\
\text { 3.3 Matorral } \\
\text { 3.4 Matorral arborescente } \\
\text { 3.5 Matorral con suculentas }\end{array}$ \\
\hline 4 & $\begin{array}{l}\text { Bosques } \\
\text { 4.1 Plantación } \\
\text { 4.2 Bosque nativo } \\
\text { 4.3 Bosque mixto }\end{array}$ \\
\hline 5 & $\begin{array}{l}\text { Humedales } \\
5.1 \text { Vegetación herbácea en orillas de ríos } \\
5.2 \text { Vegas } \\
5.3 \text { Otros terrenos húmedos }\end{array}$ \\
\hline 6 & $\begin{array}{l}\text { Áreas desprovistas de vegetación } \\
\text { 6.1 Playas y dunas } \\
\text { 6.2 Afloramientos rocosos } \\
\text { 6.3 Terreno sobrel el límite de la vegetación } \\
\text { 6.4 Corridas de lavas y escoriales } \\
\text { 6.5 Derrumbe sin vegetación } \\
\text { 6.6 Otros terrenos sin vegetación } \\
\text { 6.7 Cajas de ríos }\end{array}$ \\
\hline 7 & $\begin{array}{l}\text { Nieves eternas y glaciares } \\
7.1 \text { Nieves }\end{array}$ \\
\hline 8 & $\begin{array}{l}\text { Cuerpos de agua } \\
\text { 8.1 Rios } \\
\text { 8.2 Lagos, lagunas, embalses, tranques }\end{array}$ \\
\hline
\end{tabular}

Tabla 2: Clasificación uso del suelo. Fuente: CONAF, 2011.

Para la identificación de alternativas y mejoramiento vial en el área del Valle Lo Campino, se analizaron dos variables: densidad poblacional, y capacidad de carga potencial de las vías existentes.

La variable densidad de población fue obtenida a partir de datos públicos del Instituto INE para las 478,70 ha. Los datos utilizados fueron producidos por el Censo Nacional del año 2017 y recopilados con una resolución espacial correspondiente al de una manzana (urbana).

La variable capacidad de carga potencial fue establecida in situ a partir del número de vehículos motorizados potenciales presentes por manzanas. Dada las dimensiones del área de estudio, se identificó un tamaño de muestra para su determinación, basado en la ecuación para determinar unidades muestrales propuesta por Torres et al. (2012). Esta calculo, es considerado solo en el caso que se conozca el tamaño total de la población, es decir, la cantidad de manzanas presentes en el área de estudio que, para el caso en particular, corresponde a 97 manzanas con data correspondiente a la temporada estival del año 2018.

$$
\mathrm{n}=\frac{\mathrm{N} * \mathrm{Z}_{\mathrm{a}}^{2} * \mathrm{p} * \mathrm{q}}{\mathrm{d}^{2} *(\mathrm{~N}-1)+\mathrm{Z}_{\mathrm{a}}^{2} * \mathrm{p} * \mathrm{q}}
$$

Donde:

$\mathrm{n}$ : tamaño de la muestra buscada.

$\mathrm{N}$ : tamaño de la población (97 manzanas).

Z: nivel de confianza (90\%)

$P$ : probabilidad de éxito o proporción esperada

Q: probabilidad de fracaso.

$\mathrm{D}$ : error máximo admisible en términos de proporción (10\%).

Cuando se desconoce la probabilidad de éxito, Torres (2012), propone utilizar un criterio conversador, es decir, un $50 \%$, lo que permite maximizar el tamaño de la muestra.

Para el caso particular del presente estudio, la unidad o tamaño de la muestra corresponde a 39 manzanas.

Producto de lo anterior, se dispuso de un plan de muestreo basado en la representatividad espacial de las muestras (manzanas), denominado muestreo aleatorio simple sin reposición. Este método de muestreo permitió que, todas las muestras posibles, de un tamaño fijo, tuvieran igual probabilidad de ser seleccionada. Para obtener una muestra por este procedimiento, se enumeraron todas las unidades muéstrales, y se sortearon hasta completar el número requerido (Galbiati, 2015). Este procedimiento se realizó ingresando en una urna las posibles muestras y posteriormente extrayendo uno a una hasta completar el tamaño de muestra definido.

En lo que respecta a las alternativas $y$ mejoramientos viales, estos fueron diseñados bajo conceptos de imagen objetivo, guiado desde una perspectiva de ordenamiento y planificación 
territorial, considerando parámetros topográficos, vías estructurantes actuales, caminos en etapa de proyecto, la futura Línea 7 del Metro de Santiago y proyectos inmobiliarios en etapa de evaluación con sus respectivos proyectos viales.

La propuesta paisajística se desarrolló de acuerdo con lo establecido en la Guía de Evaluación de Impacto Ambiental aplicada al Valor Paisajístico en el Sistema de Evaluación de Impacto Ambiental (SEIA, 2013), donde fue evaluada el área de estudio, en función de puntos de observación y topografía del lugar a partir de un análisis de visibilidad o cuencas visuales. La topografía utilizada para el análisis fue obtenida desde plataformas virtuales de la Administración de la Aeronáutica y del Espacio (NASA) a partir de un Modelo de Elevación de Terreno (DEM), que permite obtener curvas de nivel del sector, consideradas también para las propuestas viales.

El análisis del área de estudio se enfocó en términos del valor paisajístico y calidad visual en función de los atributos biofísicos, estéticos y estructurales del área. A partir de estos, se desarrolló una propuesta paisajística que: respete la topografía y vegetación del lugar, defina los bordes urbanos y espacios de transición entre usos y que integre paisajísticamente desde la normativa el paisaje (Muñoz Criado, 2012). Es destacable mencionar, la relación de continuidad del Cerro Renca con el área de estudio, dado su carácter de Cerro Isla dentro de la Región Metropolitana y sus proyectos de conservación y recuperación de espacios públicos y recursos naturales.

\section{RESULTADOS Y DISCUSIÓN}

\section{SITUACIÓN ACTUAL DE ÁREA DE ESTUDIO}

En lo que respecta a la variable demográfica, principal factor junto con los instrumentos de planificación territorial, la comuna de Quilicura, donde se encuentra Valle Lo Campino, presenta un Plan Regulador Comunal en etapa de actualización, siendo el último elaborado el año 1986), por consecuencia es regido por el PRMS del año 2013, el que incorporó a la Región Metropolitana aproximadamente 10.000 ha. para desarrollo urbano, de las que cerca de 1.900 ha. se ubican en la comuna de Quilicura (Evaluación Ambiental Estratégica Quilicura, 2016)

El área de Valle, definida por las estribaciones del Cerro Renca hasta el Cerro Colorado, donde el primero es catalogado dentro de los veintiséis Cerros Isla de la Región, se encuentran desatentados paisajísticamente y a la espera de la aprobación de parte de un sistema de evaluación ambiental a futuros proyectos inmobiliarios, sin la posibilidad de contribuir a solventar la escasez de áreas verdes y potenciar la biodiversidad y actividades al aire libre en Santiago con su tendencia a la desertificación (Cerros Isla, 2018).

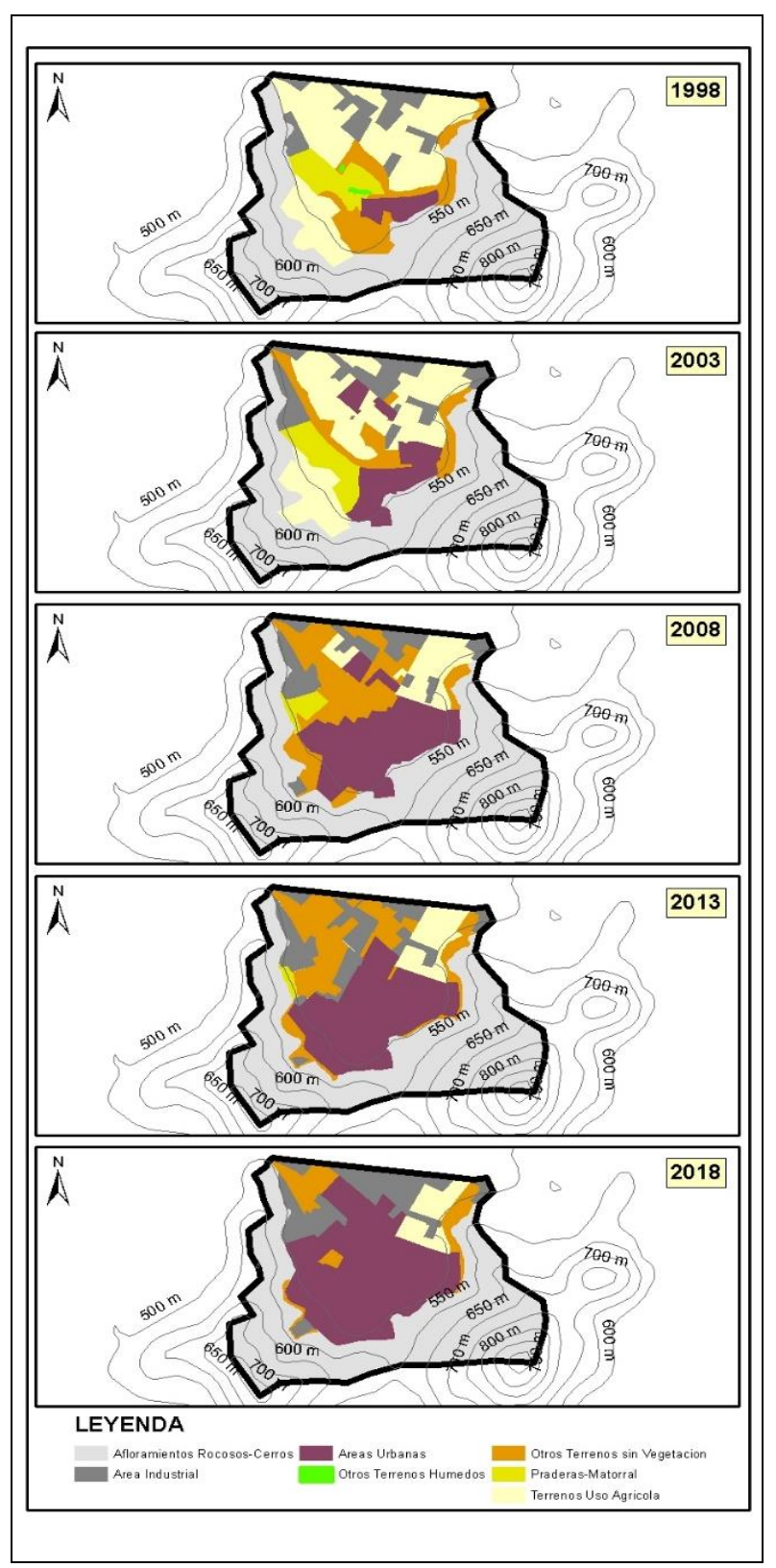

Fig. 3: Cambios de suelo entre periodo 1998-2018, en Valle Lo Campino. Fuente: Elaboración propia, 2018. 
En lo que respecta a la cuantificación de los cambios de suelo, estos son presentados a través de una tabla o matriz de confusión (Tabla 2).

\begin{tabular}{|c|c|c|c|c|c|}
\hline \multirow{2}{*}{$\begin{array}{l}\text { USO SUELO } \\
\text { CONAF (2011) }\end{array}$} & \multicolumn{5}{|c|}{ CLASIFICACIÓN Y CUAHTIFICACIÓN ESPACIO-TEMIPORAL } \\
\hline & 1998 & 2003 & 2008 & 2013 & 2018 \\
\hline $\begin{array}{c}\text { A.floramientos } \\
\text { Rocosos-Cerros }\end{array}$ & 240,78 & 229,79 & 233,36 & 228,05 & 225,95 \\
\hline Área Industrial & 33,36 & 42,22 & 38,7 & 49,87 & 55,2 \\
\hline Área Urbano & 13,43 & 39,92 & 91,1 & 104,82 & 148,29 \\
\hline $\begin{array}{c}\text { Otros Terrenos } \\
\text { Húmedos }\end{array}$ & 0,43 & - & - & - & - \\
\hline $\begin{array}{l}\text { Otros Terrenos } \\
\text { sin Vegetación }\end{array}$ & 44,65 & 32,73 & 75,15 & 69,06 & 28,75 \\
\hline Pradera-Matorral & 24,23 & 22,94 & 7,99 & 2,51 & - \\
\hline $\begin{array}{c}\text { Terreno Uso } \\
\text { Agrícola }\end{array}$ & 121,82 & 111,1 & 32,4 & 24,39 & 20,51 \\
\hline TOTAL & 478,70 & 478,70 & 478,70 & 478,70 & 478,70 \\
\hline
\end{tabular}

Tabla 2: Matriz de confusión que presenta los cambios de coberturas de suelo de forma cuantitativa expresadas en hectáreas.

La Tabla 2, permite dimensionar numéricamente las modificaciones presentadas y descritas en la Fig. 3, producto del análisis multitemporal. Esta tabla, evidencia el aumento de cobertura urbano en 134,86 ha y 21,84 ha de cobertura industrial, en desmedro principalmente de los terrenos de uso agrícola, los que disminuyeron 131,31 ha en las últimas dos décadas. Otros casos presentes son la ausencia del uso denominado pradera-matorral y la disminución de 14,83 ha de afloramientos rocosos, considerados sectores netamente de cerros, unidad que define el valle y que se ha visto afectada por el avance urbano-inmobiliario.

Paralelamente a la data cualitativa y cuantitativa, se determinó una tasa de cambio anual, definido por la FAO para la totalidad de los usos de suelo identificados en los periodos de estudio presentados en la Tabla 3.

\begin{tabular}{|c|c|c|c|c|}
\hline $\begin{array}{c}\text { TASA CAMBIO ANUAL \% } \\
\text { (FAO, 1996) }\end{array}$ & $\mathbf{1 9 9 8 - 2 0 0 3}$ & $\mathbf{2 0 0 3 - 2 0 0 8}$ & $\mathbf{2 0 0 8 - 2 0 1 3}$ & $\mathbf{2 0 1 3 - 2 0 1 8}$ \\
\hline $\begin{array}{c}\text { A.floramientos Rocosos- } \\
\text { Cerros }\end{array}$ & $-0,93$ & 0,31 & $-0,46$ & $-0,19$ \\
\hline Área Industrial & 4,82 & $-1,72$ & 5,20 & 2,05 \\
\hline Área Urbana & 24,34 & 17,94 & 0,03 & 7,19 \\
\hline Otros Terrenos Húmedos & - & - & - & - \\
\hline $\begin{array}{c}\text { Otros Terrenos sin } \\
\text { Vegetación }\end{array}$ & $-6,02$ & 18,09 & $-1,68$ & $-16,08$ \\
\hline Pradera-Matorral & $-1,09$ & $-19,02$ & $-20,67$ & - \\
\hline Terreno Uso Agrícola & $-1,83$ & $-21,84$ & $-5,52$ & $-3,41$ \\
\hline
\end{tabular}

Tabla 3: Tasa de cambio anual para los usos de suelo urbano e industriales según definición establecido por la FAO.
La tasa de cambio anual es una forma ejecutiva para presentar los datos y permite conocer las tendencias en los procesos de cambio de uso, estableciendo un análisis a futuro para la toma de decisiones en lo que respecta a la planificación territorial urbana, específicamente vial. Se infiere que, el principal cambio de cobertura de suelo corresponde al área urbana, el cual continuará en expansión, en desmedro del sector agrícola y afloramientos rocosos, produciendo aumento de población, disminución de la capacidad de carga vial e impacto en el paisaje por afectación de áreas de cerros. Por otra parte, el uso industrial presenta una leve tendencia al avance

El número de habitantes del área de estudio y la densidad poblacional al momento del estudio, no pudo ser obtenido por las fuentes citadas, por tanto, para continuidad del estudio, se estableció lo señalado por la Ordenanza General de Urbanismo y Construcción (OGUC) en el Artículo 2.2.5, que indica que, para el cálculo de densidad de proyectos de loteos, se debe considerar cuatro habitantes por viviendas. Las viviendas del área de estudio de acuerdo con antecedentes bibliográficos, cartografía y apoyo de terreno, corresponde a 3.497 viviendas. En consecuencia, el número de habitantes para el área de estudio corresponde a 13.988 , equivalente al $6,65 \%$ del total comunal de acuerdo con el Censo 2017 (Tabla 1).

La capacidad de carga potencial está dada por un conteo in situ e vehículos motorizados, el factor o número de vehículos promedios por manzanas fue de 1,5 vehículos por viviendas, lo que resultó en un total de 5.246 vehículos en el área de Valle Lo Campino.

Ambas variables, llámese población y capacidad de carga potencial y los cambios de coberturas de suelo (principalmente urbano e industrial) son claves para la determinación y justificación de alternativas y/o mejoramientos viales para el sector del Valle Lo Campino. En los últimos veinte años la población aumentó en alrededor de 12.000 habitantes en conjunto con una expansión del área urbana que supera las 100 ha. De acuerdo con imágenes históricas, las vías de acceso y conectoras a vías estructurantes como la autopista Vespucio Norte, siguen siendo las mismas (Fig. 4). Si bien esta y otras autopistas exhiben mejoras en amplitud y temporalidad, aún son insuficientes para la necesidad del área. 


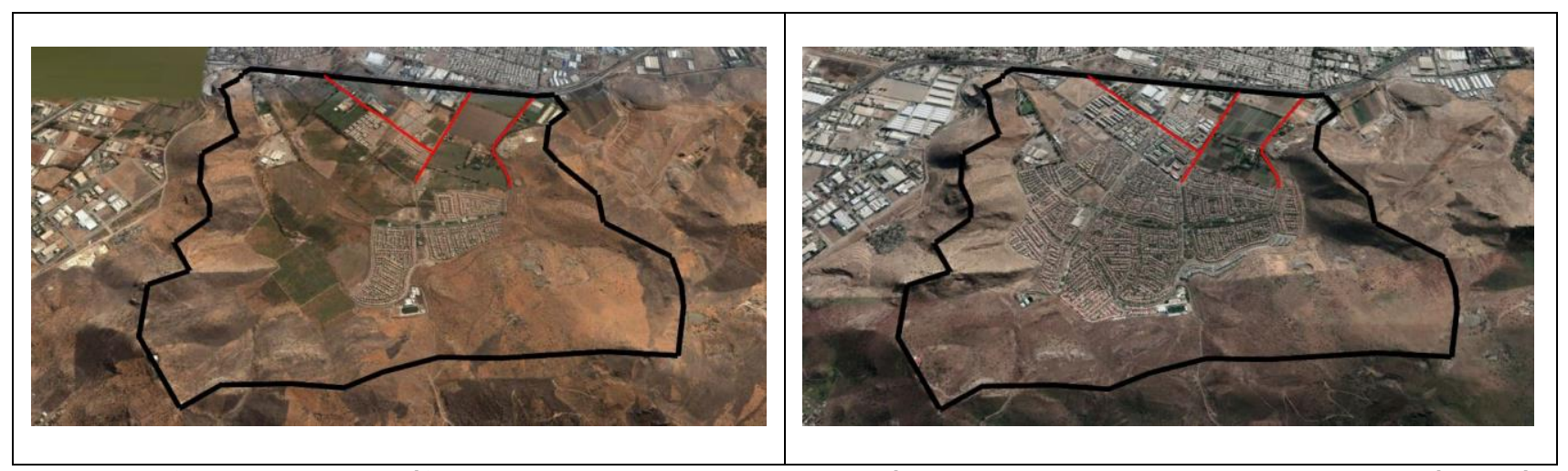

Fig. 4: La figura presenta gráficamente el avance urbano en el área de estudio y se destacan la conexión a vías estructurantes, las que no presentan modificaciones en los periodos de estudio. Fuente: Google Earth. Fuente: Elaboración propia, 2018.

Las alternativas viales propuestas están vinculadas a la conectividad del área de estudio a las vías principales, llámese Autopista Central y Vespucio Norte y no a la circulación interna del Valle Lo Campino. Bajo esta premisa, la Figura 5 (Fig. 5) presenta nueve propuestas que permiten la movilidad al exterior del área de estudio, las cuales consideran variables topográficas, caminos, senderos existentes, y vías de comunicación futuras como es la Línea 7 de la red de metro de Santiago, todas con una doble vía o dirección. Dentro del ciclo de vida de un proyecto vial, esta etapa corresponde a fase de estudio, específicamente idea, perfil y estudio preliminar.

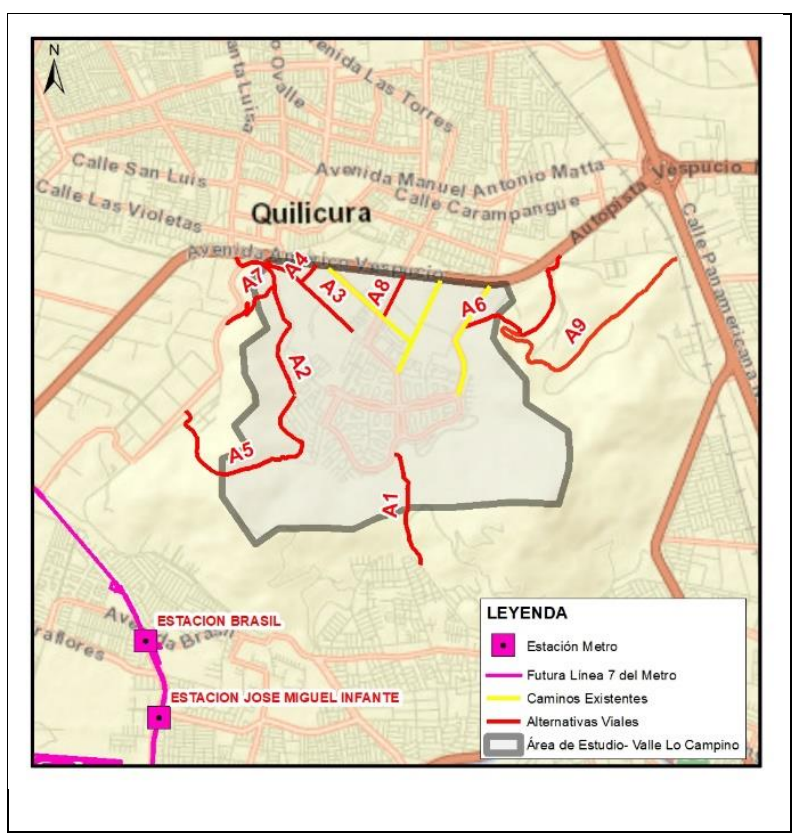

Fig.5: Propuestas viales de conexión para el Valle Lo Campino. Fuente: Google maps. Fuente: Elaboración propia, 2018.
La alternativa denominada $A 1$, corresponde a una vía de conexión al sur del área, cuya finalidad es conectarse a la Autopista Central, Costanera Norte y a la futura Línea 7 del metro estación Brasil. Actualmente, este camino es de bajo tránsito y solo apto para vehículos pesados o con tracción. La alternativa A5, ubicada al poniente, presenta conectividad para Vespucio Norte, estación del metro Brasil y camino interior dirección Aeropuerto. Las alternativas A2, A3, A6, A7 y A8, son vías de salidas directa a Vespucio Norte. La alternativa A9, ubicada en el sector oriente, es la más ambiciosa, tanto por extensión $(2,3 \mathrm{~km})$ como por la pendiente promedio de un $8,9 \%$ cuya conectividad seria directa a la Autopista Central. El anexo 2 del estudio presenta cartografía temática con los resultados a escalas variadas

La variable paisaje y su aplicación metodológica, fue establecida de acuerdo con la Guía de Evaluación Ambiental (SEA) y consta de tres aristas. La primera, definición de cuencas visuales (Fig. 6), es decir, porción de terreno visible desde un determinado punto (SEA, 2013) a partir de puntos de observación definidos en terreno distribuidos en el área de trabajo (Tabla 4).

\begin{tabular}{|c|c|c|c|c|c|}
\hline \multirow{2}{*}{$\begin{array}{c}\text { PUNTO } \\
\text { OBSERVACIÓN }\end{array}$} & \multicolumn{2}{|c|}{ UTM-WGS84 HUSO 19s } & \multirow{2}{*}{\begin{tabular}{|c|} 
PUNTO \\
OBSERVACIÓN \\
\end{tabular}} & \multicolumn{2}{|c|}{ UTM-WGS84 HUSO 19s } \\
\hline & ESTE & NORTE & & ESTE & NORTE \\
\hline P01 & 338.773 & 6.305 .987 & P010 & 339.666 & 6.304 .873 \\
\hline PO2 & 340.012 & 6.305 .916 & P011 & 340.154 & 6.304 .970 \\
\hline $\mathrm{PO} 3$ & 340.366 & 6.305 .862 & P012 & 339.063 & 6.304 .747 \\
\hline PO4 & 338.992 & 6.305 .337 & P013 & 339.690 & 6.304 .660 \\
\hline PO5 & 339.400 & 6.305 .387 & P014 & 339.311 & 6.304 .403 \\
\hline PO6 & 339.654 & 6.305 .185 & PO15 & 338.407 & 6.304 .515 \\
\hline PO7 & 340.157 & 6.305 .080 & P016 & 339.853 & 6.304 .099 \\
\hline PO8 & 338.815 & 6.304 .994 & P017 & 337.839 & 6.306 .104 \\
\hline PO9 & 339.190 & 6.304 .976 & P018 & 341.104 & 6.306 .279 \\
\hline
\end{tabular}

Tabla 4: Coordenadas de puntos de observación dentro del Valle Lo Campino y sus alrededores. Fuente: Elaboración propia 


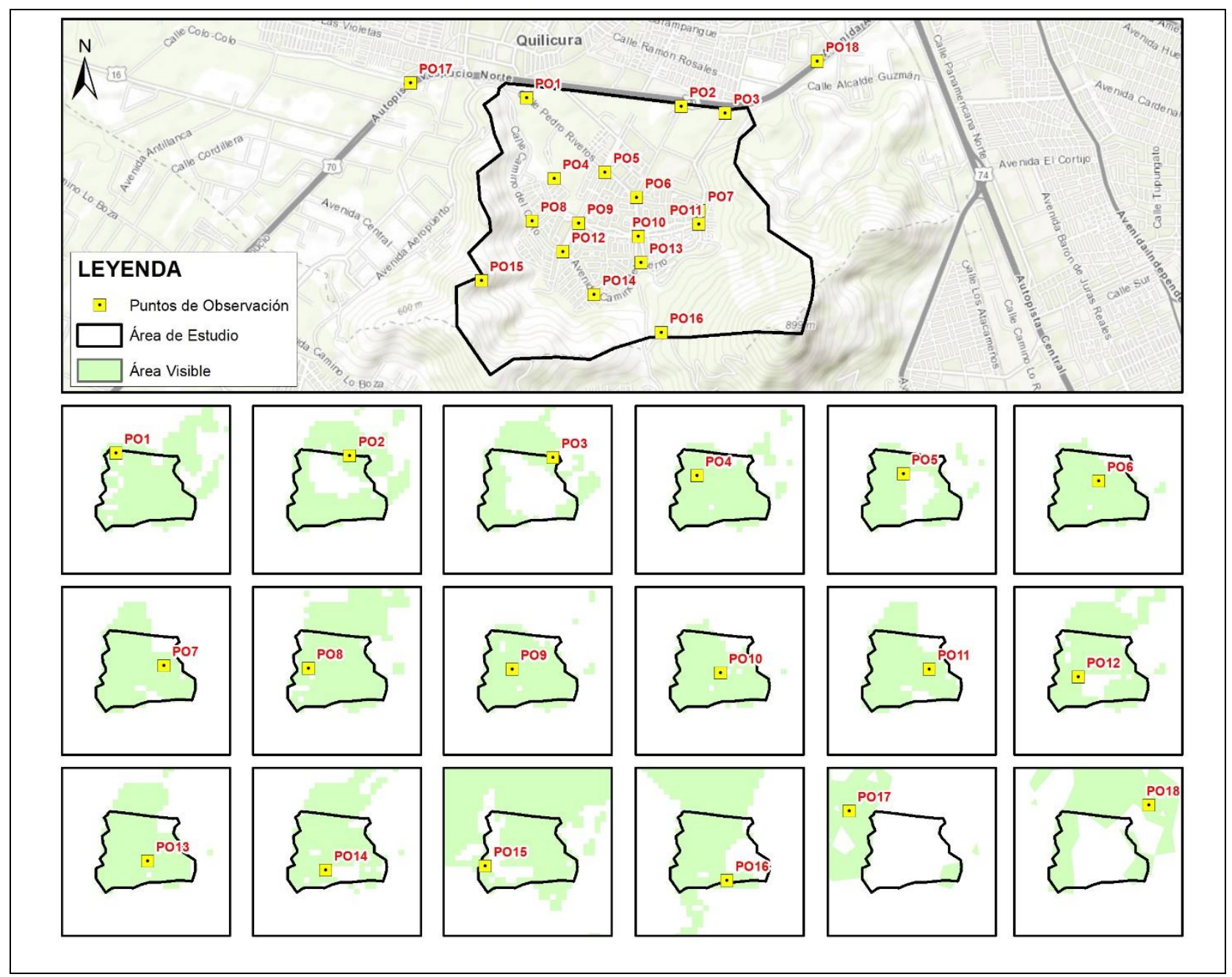

Fig. 6: Puntos de observación definidos en terreno y distribuidos en el área de estudio y sus alrededores y cuencas visuales asociadas al punto. Fuente: Fuente: Elaboración propia, 2018.

Otero et. al. (2009), señala que la mayoría de los enfoques aplicados al análisis visual del paisaje, conceden gran importancia a la determinación de las áreas de visibilidad desde los distintos puntos de vista. En el caso particular del estudio, de los dieciocho puntos de observación, un 100\% presenta visibilidad hacia el Cerro Colorado y Renca que definen el Valle Lo Campino, por consecuencia es un elemento considerado a destacar, donde cualquier intervención tendrá un impacto visual alto y deberán presentar medidas de mitigación. Las cuencas visuales fueron obtenidas en función de Modelos Digitales de Elevación (DEM), y procesos geomáticos en el Sistema de Información Geográfica ArcGis 10.4.1, módulo Spatial Analyst.

La segunda arista, corresponde a la determinación del valor paisajístico del área (Tabla 5), es decir, aquella que, siendo perceptible visualmente, posee atributos naturales que le otorgan una calidad que la hace única y representativa (Guía de Evaluación Ambiental, 2013).

\begin{tabular}{|c|c|}
\hline \multicolumn{2}{|c|}{$\begin{array}{l}\text { DETRERMINACIÒN DE VALOR PAISAJÍSTICO SEGÚN ATRIBUTOS } \\
\text { BIOFÍSICOS }\end{array}$} \\
\hline TIPO DE ATRIBUTO & CARACTERISTICA QUE OTORGA VALOR \\
\hline Relieve & $\begin{array}{l}\text { Tipo: Valle Colina - Pendiente } 0-15 \% \text { en Valle, Superior a } \\
30 \text { en Colina - Orientacion Solana }\end{array}$ \\
\hline Suelo & Pedregoso y Terrazas remanentes \\
\hline Agua & - \\
\hline Vegetación & $\begin{array}{c}\text { Cobertura menor } 30 \% \text { - Temporalidad permanente - } \\
\text { Diversidad media, presencia de Porlieria chilensis } \\
\text { (guayacan), Acacia caven (espino), Quillaja saponaria } \\
\text { (Quillay) y Prosopis chilensis (Algarrobo). }\end{array}$ \\
\hline Fauna & Avistamiento de aves - Presencia y Abundancia baja \\
\hline Nieve & - \\
\hline
\end{tabular}

Tabla 5: Determinación valor paisajístico de acuerdo a Guía de Evaluación de Paisaje (SEA, 2013). 
De acuerdo con los resultados obtenidos in situ vía pedestre, presentados en la tabla 5 , ex post, y el apoyo en gabinete de modelos de pendiente, orientación, coberturas espaciales de suelo y vegetación; se determinó que el área de estudio evaluada tiene valor paisajístico, a pesar de no presentar todas las características biofísicas que se esperan de un área de esta naturaleza. En este caso, las guías de evaluación señalan que: es necesario solo la ocurrencia de un atributo para considerar el área con un valor paisajístico. En este caso en particular, esta connotación fue principalmente otorgada por las características del relieve, dado por el Valle, la vegetación predominante en las zonas de quebradas y la avifauna.

La tercera arista metodológica del paisaje corresponde a la calidad visual de paisaje, no sin antes destacar que, el paisaje, tiene un valor intrínseco y su calidad se puede definir en función de su calidad visual consustancial, de la calidad de las vistas directas que desde él se divisan y el horizonte escénico que lo enmarca. Así, la calidad del paisaje se define por el conjunto de características visuales y emocionales que califican la belleza del paisaje (Cifuentes, 1989).

La tabla 6 presenta las características biofísicas, estéticas y estructurales, que definen la calidad visual del área, de acuerdo a lo señalado en la Guía de Evaluación de Impacto Ambiental para el Valor Paisajístico (Página №36, Tabla 6).

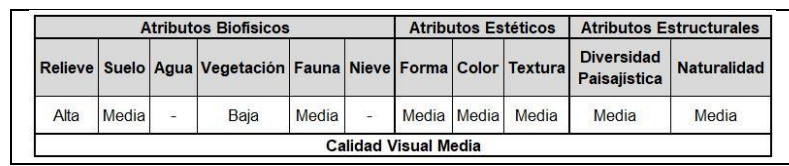

Tabla 6: Determinación calidad visual de acuerdo con Guía de Evaluación de Paisaje (SEA, 2013).

En función de los resultados, la calidad visual para el área de estudio es considerada de valor medio.

La sumatoria de los análisis, es decir, cuencas visuales a través de puntos de observación que identifica al cordón de cerros que rodea al valle como dominante en el paisaje, el análisis en terreno y gabinete a partir de técnicas y procedimientos geomáticos que determina el valor paisajístico a partir de variables biofísicas y la calidad visual que considera atributos estéticos y estructurales y la connotación de ser parte de los 26 Cerros Islas de la Región Metropolitana (Fig. 7) definido por la fundación sin fines de lucro Santiago Cerros Isla, entregan un valor potencial al área y al Cerro Renca que lo define junto a sus estribaciones hasta el
Cerro Colorado para desarrollar una propuesta paisajística.

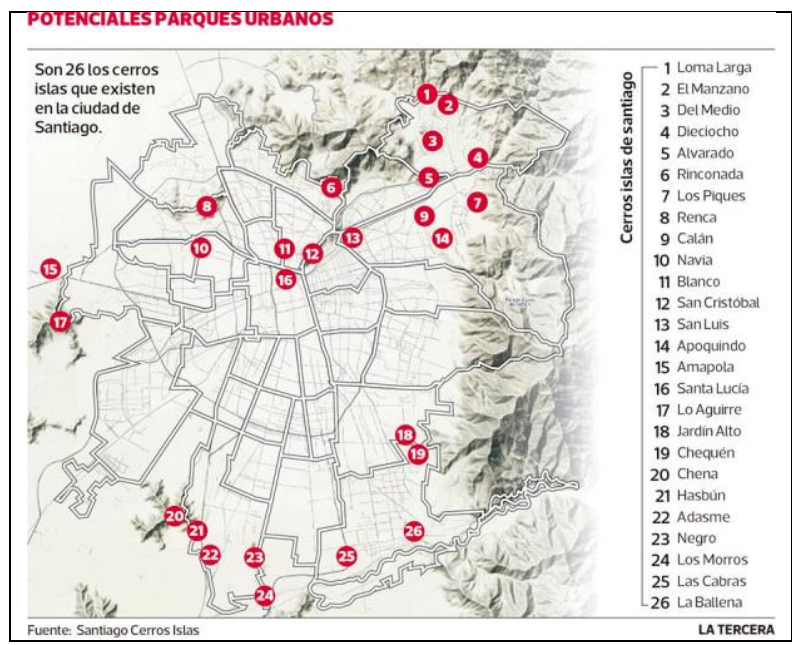

Fig.7: Cerros Isla en Región Metropolitana. Fuente: Diario la Tercera, Fecha 18 de abril 2014.

La propuesta paisajística para potenciar el cerro y por consecuencia el valle y su área urbana, es principalmente a través de sectores de reforestación, arboretum, senderos para trekking con zonas de descanso, señaléticas y miradores. Tal como se muestra en la Figura 8.

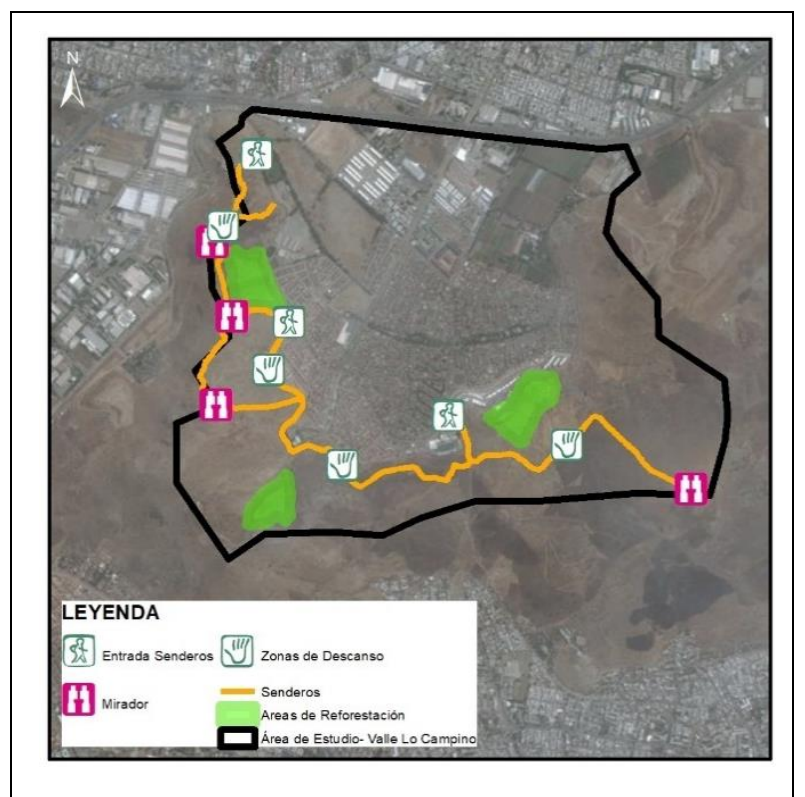

Fig.8: Propuesta paisajística para el área de Valle Lo Campino. Fuente: Elaboración propia. 


\section{CONCLUSIONES}

Dada las características espaciales del área de estudio y el carácter principalmente urbano e industrial que presenta, el análisis multitemporal permitió analizar cualitativita y cuantitativamente los cambios de coberturas de suelo en un periodo de veinte años, quedando de manifiesto los avances urbanos en el área en desmedro de sectores agrícolas principalmente con un crecimiento superior a las 100 ha en veinte años.

Este importante crecimiento no había sido considerado en los instrumentos de ordenamiento territorial de la comuna hasta el año 2017, donde, por medio de la aprobación de la enmienda al PRC se establece una "corrección" al instrumento que no había sido actualizado desde el año 1985. Esta falta de actualización hizo que se aprobaran una serie de proyectos inmobiliarios como el Valle Lo Campino, pero sin considerar los problemas que trae consigo la densificación poblacional en el territorio. Las vías de conexión se vieron seriamente afectadas ocasionando problemas de transporte serios a los residentes de las nuevas poblaciones que se construían año tras año.

Es aquí donde el conocimiento de patrones de distribución urbana y los cambios en las coberturas de suelo puede resultar ser cruciales para una correcta planificación urbana. Sumado a los anterior, datos como el número de habitantes y la cantidad de potenciales vehículos, son utilizado como antecedentes que fundamenten problemáticas propias de este tipo de estructuras urbanas y son el input base para la resolución de las mismas, aportando a la identificación y mejoramiento de alternativas viales.

El presente estudio, en función de lo expuesto con anterioridad, propone nueve alternativas de conectividad a vías estructurantes, ya sean a la autopista Vespucio Norte como también a la futura línea 7 del metro de Santiago. Si bien esta última no es de forma directa, es de acercamiento a una vía paralela que facilita la movilidad fuera del Valle Lo Campino. De esta forma se cumple con uno de los objetivos específicos y colaborar a la etapa de diagnóstico para futuros proyectos viales.

En términos paisajísticos, el Cerro Renca y sus estribaciones que definen el Valle Lo Campino, es considerado un Cerro Isla dentro de la Región y por consecuencia un polo de desarrollo a nivel urbano. El crecimiento y expansión de ciudades suelen dejar en una suerte de abandono los lugares con potencial valor paisajístico. La construcción de nuevas poblaciones, generalmente, suelen planificar sólo las áreas verdes que se encuentran integradas al proyecto inmobiliario, y las leyes actuales vigentes en el país no les obligan a hacerse cargo de las áreas aledañas a ellas, por tanto, se interviene un territorio donde generalmente se requiere una aprobación de cambio de uso de suelo para convertirlo en residencial, pero no se contempla que la población que ahí vivirá puede optar a tener espacios naturales que fomenten la actividad al aire libre y mejoren la calidad de vida de sus habitantes. En este estudio quedó en evidencia la potencialidad paisajística y armoniosa que presenta, donde se propone la generación de circuitos de treking, miradores, arboterun y reforestaciones, siendo estas diseñada en función de experiencias similares dentro del país.

Dado lo anterior, surge nuevamente la necesidad de contar con un PRC actualizado, donde se realice un estudio acabado de la comuna y no sólo se considere una enmienda que no cubre todas las necesidades territoriales de la comuna. De esta forma, también se evidencia la falta de planificación conjunta entre los distintos municipios limítrofes en términos de continuidad de usos de suelo y planificación de expanción poblacional. Por otra parte, las zonas "no urbanas" no tienen regulación bajo este tipo de instrumentos, lo que va en perjuicio de la conservación adecuada de las mismas.

Si bien, el PRMS establece las bases para la planificación en todas las comunas de la Región Metropolitana, la escala de trabajo es inferior a la requerida a la hora de planificar en términos de uso de suelo, conservación adecuada de áreas naturales y desarrollo comunal.

\section{REFERENCIAS}

Bocco, G. Mendoza, M. y Masera, O. (2001). La Dinámica del Cambio del Uso del Suelo en Michoacán. Una Propuesta Metodológica Para el Estudio de los Procesos de Deforestación. Investigaciones Geográficas. Boletín del Instituto de Geografía. UNAM. Ciudad de México, México.

Borsdorf, A. (2000). El Desarrollo Urbano de Valdivia. Estudio de Caso en una Cuidad Mediana Chilena. Espacio y Desarrollo. pp 12,45,82. Santiago, Chile. 
Caldeira, T. (2000). Citu of Walls: Crime, Segregation, and Citizenship in Sao Paulo. University California. California, EE. UU.

Cerquera, F. (2007). Capacidad y Niveles de Servicio de la Infraestructura Vial. Universidad Pedagógica y Tecnológica de Colombia. Tunja, Colombia.

Cifuentes, P. 1989. La Calidad Visual de Unidades Territoriales. Tesis Doctoral. Universidad Politécnica de Madrid. Madrid, España.

CONAF, 2011. Catastro y Evaluación de los Recursos Vegetacionales Nativos de Chile. Proyecto CONAF/CONAMA/BIRF. Santiago, Chile.

Cooper, M. (2007). Territorios Metropolitanos y Territorios al Margen. Revista CA, Arquitectura y cuidad. Número 131. Santiago, Chile.

Cross, V. (2016). Revista Digital Ladera Sur. Edición de Octubre. Santiago, Chile.

Cuadrado, S. (2016). Dispersión Metropolitana, Urbanización del Medio Rural y Transformación de los Espacios Turísticos en la Europa Mediterránea. Revista Bibliográfica de Geografía y Ciencias Sociales. Barcelona, España.

FAO. (1996). Forest Resiurces Assessment 1990. Survey of Tropical Forest Cover and Study of Change Processes. Number 130. Roma, Italia.

Galbiati, R. (2015). Conceptos Básicos de Estadística. Pontificia Universidad Católica de Valparaíso. Valparaíso, Chile.

García, A. Martínez, G. Núñez, G y Guzmán, A. (1998). Clasificación Supervisada Inducción de Arboles de Decisión. Instituto Politécnico Nacional, Centro de Investigación en Computación. Cuidad México, México.

García-Meléndez, E. Análisis Visual de Imágenes. Módulo VII: Sistemas de Información Geográfica y Teledetección. Master en Ingeniería Medioambiental y Gestión del Agua 2006/2007.Universidad de León. León, España.Greene, M. y Soler, F. (2002). Santiago: De un Proceso Acelerado de Crecimiento a uno de Transformaciones. Universidad Católica de Chile. Santiago, Chile.
Hurtubia, R. Cox, T. (2017) Expansión Urbana y Accesibilidad. Plataforma Urbana. Santiago, Chile.

INE. (2005). Estimaciones a Partir de INEGI, XII Censo General de Población y Vivienda, 2000; y Conapo (2002), Proyecciones de la Población de México, 2000-2050. México.

Morales, J.P. (2011). La Capacidad de Carga: Conceptos y Usos. Revista Recursos Naturales y Ambiente. Centroamérica.

MOP, 2011. Guía para la Elaboración de Planes. Subdirección de Planificación Estratégica. Dirección de Planeamiento. Santiago, Chile.

Munzenmayer, J. (2017). La Expansión Urbana y la Segregación Socio-espacial en Santiago. Dimensiones Territoriales del Fenómeno Contemporáneo. Espacio Revista de Geografía. Universidad Academia de Humanismo Cristiano. Santiago, Chile.

Muñoz Criado, A. (2012). Guía Metodológica. Estudios de Paisaje. Conselleria de Infraestructuras, Territorio y Medio Ambiente. Valencia, España.

Otero, I. Varela, E. Mancebo, S. Ezquerra, A. (2009). El Análisis de Visibilidad en la Evaluación de Impacto Ambiental de las Nuevas Construcciones. Universidad Politécnica de Madrid. Madrid, España.

Romero, H. y López, C. (2007). Variaciones de la Funcionalidad Ambiental del Mosaico de Paisaje Vegetal del Gran Santiago entre 1975 y 2007. Universidad de Chile. Santiago, Chile.

Sánchez, R. (2013). Las Dinámicas Urbanas. Revista de Geografía Norte Grande. Instituto Geografía. Universidad Católica. Santiago, Chile.

Sánchez-Zamora, P. Gallardo-Cobos, R. Ceña Delgado, F. (2016). La noción de resiliencia en el análisis de las dinámicas territoriales rurales: una aproximación al concepto mediante un enfoque territorial. Pontificia Universidad Javeriana de Bogotá. Bogotá, Colombia.

SEA. (2013). Guía de Evaluación de Impacto Ambiental. Valor Paisajístico en el SEIA. Santiago, Chile. 
Sustentable. S.A. (2016). Línea de Base Medio Humano y Físico. Estudio de Impacto Ambiental Proyecto Inmobiliario "Mirador de Lo Campino.

Torres, M. Paz, K. Salazar, F. (2012). Tamaño de una Muestra para una Investigación de Mercado. Universidad Rafael Landivar. Facultad de Ingeniería. Cuidad de Guatemala, Guatemala.

Vásquez, M. (2009). La Geomática y su Importancia en el Desarrollo de los Estados. Revista de Marina. Viña del Mar, Chile. 